\title{
Marginally effective medical care: ethical analysis of issues in cardiopulmonary resuscitation (CPR)
}

\author{
Mark Hilberman, Jean Kutner, Debra Parsons, and Donald J Murphy The Carbondale Clinic, Carbondale, \\ Colorado, University of Colorado Health Sciences Center, St Foseph's Hospital, and the Colorado Collective for \\ Medical Decisions, Denver, Colorado, USA
}

\begin{abstract}
Outcomes from cardiopulmonary resuscitation (CPR) remain distressingly poor. Overuse of CPR is attributable to unrealistic expectations, unintended consequences of existing policies and failure to honour patient refusal of CPR. We analyzed the CPR outcomes literature using the bioethical principles of beneficence, non-maleficence, autonomy and justice and developed a proposal for selective use of $C P R$.

Beneficence supports use of $C P R$ when most effective. Non-maleficence argues against performing CPR when the outcomes are harmful or usage inappropriate. Additionally, policies which usurp good clinical judgment and moral responsibility, thereby contributing to inappropriate CPR usage, should be considered maleficent. Autonomy restricts $C P R$ use when refused but cannot create a right to $C P R$.

fustice requires that we define which medical interventions contribute sufficiently to health and happiness that they should be made universally available. This ordering is necessary whether one believes in the utilitarian standard or wishes medical care to be universally available on fairness grounds.

Low-yield CPR fails justice criteria.

Cardiopulmonary resuscitation should be performed when justified by the extensive outcomes literature; not performed when not desired by the patient or not indicated; and performed infrequently when relatively contraindicated.
\end{abstract}

\section{Introduction}

Cardiopulmonary resuscitation (CPR) can be extraordinarily successful. During heart surgery and electrophysiological studies the heart is stopped and started, with uniform success. Otherwise, recovery from cardiac arrest remains unlikely. Cardiopulmonary resuscitation represents the opportunity for life when cardiac arrest occurs. Yet it remains simply an intervention which is neither intrinsically

\section{Key words}

Ethics; bioethics; cardiopulmonary resuscitation; CPR; clinical decision-making; death and dying. effective nor benign. Use of this intervention can restore good health and wellbeing to some survivors while the overall benefit to others is low and some are left significantly impaired.

Existing guidelines promote CPR to restore life when cardiac arrest occurs from cardiac causes. ${ }^{1}$ Statutes which give an implied consent to emergency treatment are used to endorse CPR as the default response to cardiac arrest. It has become common policy to require CPR unless CPR is explicitly refused $^{23}$ or futile. ${ }^{4}$ Yet, cardiac arrest normally accompanies death and an extensive medical literature supports selective use of CPR. ${ }^{5}$ Cardiopulmonary resuscitation is not an appropriate response to death which occurs as a consequence of advanced age or illness. ${ }^{78}$

Two anecdotes illustrate limitations in the current Do Not Resuscitate (DNR) approach:

1. A university hospital cardiac resuscitation team, composed of house physicians, nurses and respiratory therapists, arrived at the bedside of a ninetyyear-old with advanced cancer whose heart had stopped. A DNR order had not been written, and hospital policy required the resuscitation team to proceed with CPR despite their grave medical and moral reservations. An attending physician relieved them of this burdensome policy requirement.

2. A robust 60 -year-old was admitted to hospital with vague chest pains for diagnosis and treatment. After evaluation he was questioned about his CPR preferences, a new conversation promoted by American laws intended to promote refusal of burdensome life-prolonging interventions. He indicated that he did not wish CPR and a DNR order was written. Within the hour he developed ventricular fibrillation (a treatable, lethal cardiac rhythm disturbance.) Simple electrical defibrillation would have been life-saving. However, the staff felt compelled not to intervene due to the DNR order and were prepared to let him die. Fortunately, his heart spontaneously reverted to a normal rhythm. When asked a second time, the patient changed his mind.

When people are under stress it is unrealistic to 
expect consistently sound decision-making. Patients who will not benefit from CPR usually benefit from other medical and nursing care. However, a written DNR order may represent "giving up" to patients, families and providers. For example, $92 \%$ of neurologists surveyed indicated that a DNR order for a stroke patient implied withdrawal of other treatment and nutrition. ${ }^{9}$ Neurologists make the same linkage for patients in a vegetative state. ${ }^{10}$

A CPR paradigm must recognize the complexity of the clinical environment and the importance of provider judgment and must respect patient autonomy. The heart can stop in patients at any age and in conjunction with many underlying illnesses and the rules should facilitate prompt, effective and appropriate CPR. In this paper we present our analysis of CPR issues using the four bioethical principles of beneficence, non-maleficence, autonomy and justice. ${ }^{11}$

\section{Beneficence}

Moral agents should take positive steps to help others. In medicine this normally involves the restoration of health and function and the relief of pain and suffering. These goals were clearly accomplished in the early steps towards effective resuscitation: in the late 1940 s and early 50 s respiratory intensive care increased survival in bulbar poliomyelitis from about $15 \%$ to over $50 \% .^{12}{ }^{13}$ A decade later, 14 of 20 patients $(70 \%)$ treated by closed chest cardiac massage survived intact. ${ }^{14}$ However, investigators who followed Kouwenhoven et al at Johns Hopkins subsequently reported hospital discharge rates of $14 \%$ in $1985,{ }^{15}$ and below $10 \%$ in $1994 .{ }^{16}$ The success rate of $70 \%$ was never duplicated. ${ }^{56}$

The greatest benefit from CPR, with survival rates over $20 \%$, was reported when cardiac arrest occured during anaesthesia, from drug overdose, and with coronary disease or a primary ventricular arrhythmia. ${ }^{56}$ A 1995 hospital discharge rate of only $17 \%$ followed CPR in coronary care unit patients, who are closely monitored and by skilled staff. ${ }^{17}$ The treatment goal is to prevent cardiac arrest, which frequently represents therapeutic failure and difficult disease.

Patients survive CPR infrequently when noncardiac major illness or organ dysfunction precede cardiac arrest. Cardiopulmonary resuscitation survival is extremely poor $(<5 \%)$ when cardiac arrest occurs in patients with renal failure, cancer (unless disease is minimal), or AIDS; and in the absence of irreversible underlying illness, following trauma, haemorrhage, sustained hypotension or pneumonia. ${ }^{561819}$ Limiting use of CPR improved results in cancer patients who had a $10.5 \%$ postCPR survival when $7-10 \%$ of those who arrested received $C P R .{ }^{20}$

Field CPR promptly initiated in the streets of Seattle resulted in a $36 \%$ hospital survival rate, the best in the recent literature. ${ }^{21}$ In other systems the results are so poor that the whole endeavour shouls be reconsidered. Specifically, fewer than $2 \%$. survive field CPR to hospital discharge in Chicago $\vec{\Rightarrow}$ or New York, due to traffic-delayed initiation of resuscitation. ${ }^{22} 23$

\section{Non-maleficence}

We wish to examine the admonition to "do nơ" (deliberate) harm" in terms of outcomes, policies $\vec{\rho}$ and appropriateness.

\section{OUTCOMES}

The incidence of brain injury following CPR varies from $10-83 \% .^{24-28}$ In one study, 55 of 60 childrertw died following prolonged field resuscitation; all five survivors were in persistent coma or a vegetative state at the time of hospital discharge. ${ }^{27}$ Many $\overrightarrow{0}$ patients regard severe disability following significane brain injury as worse than death. ${ }^{29}$ Cardiopulmonary $\vec{b}$ resuscitation becomes maleficent when the risk of brain injury is high.

\section{POLICIES}

American DNR policies were established to protect $\vec{b}$ patients from unilateral physician DNR decisiog ts and generally require CPR unless explici refused. ${ }^{2}{ }^{3}$ Rigid field CPR rules resulted in at lese one dramatic headline: Paramedics rush dead people to hospitals, costing millions. ${ }^{30}$ Since even a relativelyo brief interruption of blood flow to the brain or hearto results in severe injury, resuscitation can only succeed if applied promptly. Thus, Swedish inves윽 tigators reported that survival exceeded $80 \%$ with bystander CPR and ambulance arrival in less than two minutes, but was less than $6 \%$ with ambulance arrival time over six minutes or no bystande CPR. ${ }^{25}$ Nevertheless, in 1993 it was noted that Chicago paramedics were required to resuscitate. unless the victim was decapitated, in rigor mortis, of decomposing. ${ }^{23}$ In some states, emergency crews్ are bound to proceed with CPR despite evidences at the scene that CPR is not wished. In one such state, $7 \%$ of out-of-hospital resuscitations were unwanted. ${ }^{21}$

A generation ago moral responsibility was placed ${ }^{\Gamma}$ squarely upon the individual to act appropriatels regardless of orders given. Nevertheless, Americant health professionals have yielded to policies and laws which require that they provide CPR even when judgment and conscience protest. Actions an $\Phi^{5}$ policies which violate judgment and conscience should be considered maleficent.

\section{APPROPRIATENESS}

Cardiopulmonary resuscitation is a rough, som $\frac{?}{8}$ would say abusive, intervention. When life is snatched from death, this is inconsequential. However, cardiac arrest normally precedes death 
and providers are appropriately disturbed when they perform CPR on people afflicted by advanced illness, the debilities of old age, or dementia.

Age per se is not a contraindication to CPR. ${ }^{1731}$ Nevertheless, aging is associated with the accumulation of infirmities and illnesses ${ }^{7233}$ which, with long-term nursing home residence and diminished function, remain predictors of poor CPR outcome. ${ }^{20}{ }^{34-36}$ Survival to hospital discharge following CPR in public, home, and nursing home settings was $36 \%, 13 \%$ and $3 \%$ respectively, where "severe chronic disease" was present in $6 \%, 33 \%$ and $68 \%$ respectively. ${ }^{21}$

One description of nursing home CPR survivors presents the concern better than dry survival percentages:

One of the two nursing-home residents who survived was an 87-year-old woman who spent 30 days in the hospital and died eight months after returning to the nursing home, demented, cachectic, with a large sacral pressure sore. The other was an 81-year-old man who, after a 60-day hospitalization, returned to the nursing home and died there 14 days later. ${ }^{33}$

We should not treat our elders this way. Inappropriate CPR is maleficent.

\section{Net benefit, futility and the decisional problem}

What about interventions of little benefit? Who decides to use them? When a person's life is characterized by advanced illness, dependency or dementia the net benefit of CPR - few survivors with a poor quality of life - is inadequate. Cardiopulmonary resuscitation is not maleficent when net benefit is low, yet such poor outcomes are an inadequate goal for a medical intervention. Giving the patient the decision does not resolve the issue. The scientific medical enterprise depends upon evaluating therapeutic efficacy against defined goals. While issues involved in death and dying are difficult, the need for defined goals remains essential.

Physicians face similar problems when recommending any treatment. Patients commonly present problems which are more complex than the precise studies in the literature. The provider cannot be absolved of exercising necessary professional judgment both in selecting appropriate therapies and deciding how best to present this information to the individual. Cardiac arrest may force rapid decisions and preclude discussion. However, advance directives can play only a limited role in reaching a decision, as the circumstances of the arrest also determine if intervention is appropriate.

"Futile . . . 1. serving no useful purpose: ineffective, fruitless". ${ }^{37}$ Tomlinson and Brody recognized that to declare a medical intervention futile involved balancing complex uncertainties and decisional responsibilities. ${ }^{38}$ Schneiderman and Jecker explored futility and developed a quantitative definition of futility which requires that an intervention has failed the last 100 times used. ${ }^{39}$ This implies unreasonable certainty. It is better to recognize that certainty will elude us and that these decisions must involve a subjective balancing of burdens and benefits.

The argument that professional decisional responsibility is necessary is most effectively developed in The Death of Common Sense, a critique of the American desire to eliminate judgment in human affairs by developing evermore specific regulations. ${ }^{40}$ Individualized complex discussion with patient and/or family is part of the evaluation of benefits and burdens which remains essential. ${ }^{41}$ One important lesson of the twentieth century is that when the state decides these issues, it often puts its citizens in peril. Insurors (and America's "health maintenance organizations") have inherent conflicts of interest in deciding medical care, and lack both the moral capacity and the close involvement with the patient and family to make such decisions.

\section{Autonomy (liberty)}

There is widespread support for the right to refuse unwanted treatments. However, autonomy implies more and may not best characterize this principle. For Kant and Rawls an autonomous moral decision was a rational and dispassionate decision. Rawls set this forth clearly - he required that his justice rulemakers, his imaginary choosers, be ignorant of their future status in the just society. ${ }^{42}$ From autonomy some have drawn the inference that the patient should be able to demand treatment. This extension requires that we re-examine this principle and resolve two issues. First, it is clear that the patient is always concerned with the outcome of clinical decisions and is therefore not strictly autonomous even when judgment is not clouded by pain, fear or suffering. Second, it is the principle of justice which creates a right to receive something, not autonomy. ${ }^{43}$

In their most recent formulation Beauchamp and Childress more accurately present the principle as "Respect for Autonomy"11; however, we believe there are two formulations which may be superior. John Stuart Mill's On Liberty remains the most eloquent:

"The object of this essay . . . is to assert one very simple principle, ... that the sole end for which mankind are warranted, individually or collectively, in interfering with the liberty of action of any of their number, is self protection. That the only purpose for which power can be rightfully exercised over any member of a civilized community, against his will, is to prevent harm to others. His own good, either physical or moral ... [ [provides] good reasons for remonstrating with him, or reasoning with him, or persuading him, or entreating him, but not for 
compelling him or visiting any evil in case he do otherwise". ${ }^{43}$

This is wonderful and blends nicely with a professional sense of obligation to assist (educate, remonstrate, reason, persuade or entreat) the patient to make the best decision. Coercion is precluded.

In The Foundations of Bioethics, $\mathrm{H}$ Tristram Engelhardt Jr proposes two principles of biomedical ethics: I. The Principle of Permission and II. The Principle of Beneficence. If less impassioned, this discussion is up to date and shifts an impossible autonomy to necessary (and accepted) permission. ${ }^{44}$ His views are also concordant with the analysis of justice which follows.

The importance of obtaining fully informed permission has been taught in medical schools for years. When we surveyed 463 nurses, physicians and other professionals in the Denver area about CPR, 96\% respected patient refusal of CPR (unpublished observations.) Documenting permission and recognizing the right to revoke permission ensure that this critical principle is honoured. Neither respect for autonomy, respect for the patient's liberty interests, nor the principle of permission create a right to receive treatment as has been implied when autonomy per se has been taken as a trump prinicple.

Advance directives permit an individual some control over end-of-life care; however, we cannot require that the paperwork be in order to deliver good emergency medical care. As to the inappropriate use of technology, professionals are generally more willing to forgo non-beneficial care than are patients. $^{34546}$ Death occurs quite infrequently in hospitalized patients - in a cancer referral center only $1.5 \%$ of patients sustained a cardiac arrest. ${ }^{20}$ This low incidence may help explain the avoidance of routine DNR discussions.

Finally, false hope undermines the ability of the patient to make an informed judgment. Limiting CPR availability to those situations where its goals may be reasonably obtained enhances respect for liberty, autonomy and the permission process.

\section{Justice}

Moral justice considerations involve the creation of rights to receive something, the resolution of competing individual demands and the balancing of social goals. The issue is whether there should be a moral justice requirement to provide medical care to those in need on utilitarian grounds, ${ }^{43}$ or because justice as fairness requires that we mitigate the inequalities which randomly occur in life. ${ }^{42}$ The libertarian argument, that medical care should be treated like other desirable goods and left to the individual, retains validity but is less widely supported. Physicians are accustomed to sufficient societal resources to care for those in need - resources generally provided as private or governmental insurance or direct institutionalm support. None the less, to determine whether there is $\overrightarrow{ \pm}$. a moral justice requirement for a decent minimum of medical care for all $^{11}$ we must examine several import- $\vec{z}$ ant issues.

MEDICAL CARE AND HEALTH

"The medical art is proved to be good by its conduc- $\frac{\bar{\sigma}}{\bar{\sigma}}$ ing to health; ...." ${ }^{43}$ Many medical interventions $\varrho$ may not contribute to health. Americans spend hugew amounts on medical care, yet live no longer than citizens of other developed countries, ${ }^{47}$ nor much longer than American Christian Scientists, whow eschew medical care. ${ }^{48}$ Primary health determinants? include: food, clothing, shelter, clean water, immu-

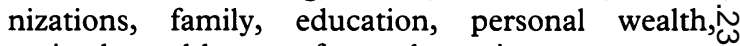
societal wealth, a safe work environment, non-क violent surroundings, personal behaviours, basic medical care and clean air. ${ }^{49-52}$

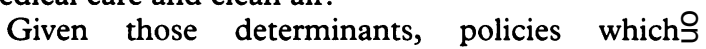
maximize health would concentrate on economic ${ }^{-}$ prosperity, safety, responsible personal behaviour and basic medical care. That leads us to a hypo- $\mathbb{\Phi}$ thetical question: under what circumstances should? we consider CPR basic, optional, experimental or므 contraindicated medical care?

\section{CAN WE AFFORD TO MAKE CPR AND OTHER} EXPENSIVE MEDICAL INTERVENTIONS UNIVERSALLYCO AVAILABLE?

The risk-sharing argument - if we each contribute $a_{0}$ small amount to the kitty, then expensive interven-응 tions can be provided to those few in need - begins $\varrho$ to fail as more and more expensive treatments are $\overrightarrow{\overrightarrow{0}}$ developed. Examples of the cost/benefit of various interventions is provided in Table 1 . As a reference, we have inserted in that table the US Gross: Domestic Product (presently approximately $\$ 25,000 /$ person/year) as it estimates available ${ }^{\circledR}$ resources and is an important determinant of the 3 amount of medical care consumed. ${ }^{47}$

Some treatments are intrinsically costly, some are 3 marginally effective and some must be repeated many times. Regulation and litigation have driven? costs upwards. All cost issues need to be addressed. While aggregate expense data are needed, it is evident that it is not possible to deliver all medicalo interventions regardless of cost or effectiveness. N Therefore, further definitions are needed before weN create a right to medical care.

\section{SOME DEFINITIONS}

It is necessary to define basic medical care in terms of outcomes or purpose. The traditional labels of medical ${ }_{+}^{+}$ necessity, ${ }^{53}$ standard and experimental therapy ${ }^{54}$ are strained by the demands of medical progress. Toه develop a preliminary definition we considered the goodness of appendectomy, penicillin for uncompli- $\frac{\mathrm{Q}}{-}$ cated pneumonia, immunizations, fracture care and hospice care. Moreover, adult cardiac operations 
Table 1 Some examples of the cost/benefit of medical care

\begin{tabular}{|c|c|c|}
\hline Treatment & $\begin{array}{l}\$ \text { Cost/year of } \\
\text { life saved }\end{array}$ & Source \\
\hline Cervical cancer screening in elderly & $(1,400)^{\star}$ & Mandelblat \& Fahs, $1988^{55}$ \\
\hline Aortic valve replacement ${ }^{56}$ & 2,800 & Hilberman $\star \star$ \\
\hline Left main coronary bypass & 6,400 & Weinstein and Stason, $1982^{57}$ \\
\hline CPR in $40 \%$ of patients with high survival & $<10,000+$ & Theimann et al, $1994^{16}$ \\
\hline Mild-moderate hypertension, beta-blocker & 10,900 & Edelson et al, $1990^{58}$ \\
\hline US GDP/person/year & $\sim \mathbf{2 5 , 0 0 0}$ & [The amount we produce each year to provide all our needs] \\
\hline End stage renal disease program & 30,000 & Levinsky $1993^{60}$ \\
\hline Cholesterol reduction with colestipol & 63,900 & Kinosian and Eisenberg, $1988^{61}$ \\
\hline Mild-moderate hypertension, ACE inhibitor & 72,100 & Edelson et al, $1990^{58}$ \\
\hline Triple vessel bypass, good heart muscle & 95,000 & Weinstein and Stason, $1985^{57}$ \\
\hline ICU care, AIDS, PCP and ventilator: $1981-91$ & 175,000 & Wachter et al, $1995^{62}$ \\
\hline ICU care for cancer: hematologic group & 189,300 & Schapira et al, $1993^{63}$ \\
\hline CCU care, low risk of MI & 208,000 & Fineberg et al, $1984^{64}$ \\
\hline CPR in $60 \%$ of patients with low survivaltt & $\sim 400,000$ & Theimann et al, $1994^{16}$, Murphy and Matchar $1990^{65}$ \\
\hline
\end{tabular}

Dollar values are as published, the assumptions of each author have not been reexamined.

*A cost savings was achieved when future treatment was considered.

$\star \star$ Using cited data source for the difference in survival between medical and surgical treatment and a cost per cardiac operation of $\$ 20,000$.

$+\$ 20,500 /$ hospital survivor, and more than half lived two years.

t†This is the cost per hospital survivor - $0 / 5$ lived two years in the Theimann study.

= approximately.

generally achieve a one-year survival $>90 \%$. By contrast some treatments for advanced breast cancer accelerate death in two of three treated. Therefore we propose that basic medical care should:

1. Prevent, cure, palliate, or yield a one-year survival greater than 75 per cent;

2. Produce little toxicity or long term disability;

3. Be affordable; and

4. Be distinctly more beneficial than burdensome.

Other therapy should be considered either optional or experimental.

Despite its preliminary nature, we believe it useful to apply this definition to CPR. As burdensome outcomes seem roughly correlated with survival, we use survival:

- $\mathrm{CPR}$, in patient groups with anticipated survival of $20-50 \%$ is experimental, generally beneficial care in need of further evaluation and refinement.

- CPR with anticipated survival of $5-20 \%$ is marginal experimental care, in need of further evaluation and refinement.

- CPR with expected survival below $5 \%$ or with delayed initiation has proven an unsuccessful experiment and is not to be performed.

\section{Summary of ethical argument}

Selective CPR is supported by consideration of the balance between burdens and benefits and of the moral requirement that known harmful actions be avoided. Decisional authority to use or withhold CPR must reside in providers who can use their training, skills and knowledge to provide the best available care. Respect for individual refusal of unwanted treatment is widely accepted. However, a demand for CPR based solely upon the patient's wishes is difficult to support. Beneficence, non- maleficence and securing permission remain the primary responsibility of providers. Justice considerations seem especially worthwhile for therapeutic evaluation and societal consideration. Justice considerations support limited use of CPR and indicate the need for better definition of medical care and the relationship of medicine to health.

\section{CPR recommendation}

Cardiac arrest must occur for CPR to be a relevant intervention, but cardiac arrest is not a sufficient indication for CPR. Since the decision not to perform CPR is irreversible, it is appropriate for there to be a bias toward its initiation. However, the extensive outcomes literature and ethical analysis justify a more limited application of CPR than do present DNR policies. Therefore, we recommend:

CPR should be performed when it is indicated.

- CPR should not be performed when it has been refused or is not indicated.

- CPR should be performed infrequently when the intervention is relatively contraindicated.

Other medical care should be provided to patients independently of resuscitation status. Providers must specifically exclude race or socioeconomic factors from consideration.

Definition: CPR means full resuscitation for cardiac or respiratory arrest, including chest compressions, ventilation, and pharmacological or electromechanical support.

CPR is indicated: 1. For witnessed arrests. 2. For a cardiac rhythm of ventricular fibrillation or tachycardia; 3. During operations and procedures; and, 4. As part of well justified experimental protocols.

$C P R$ is not obligatory.

CPR is not indicated: 1 . If the patient does not want CPR. 2. If the arrest is unwitnessed, unless 
some sign of life persists; 3 . If CPR is not started within six minutes of the arrest, or has continued more than 30 minutes (except hypothermia); 4. For patients in a Persistent Vegetative State, in coma, or with severe heart or lung failure, advanced cancer, or other end-stage illness.

CPR is relatively contraindicated: 1 . If it is known that the patient had significant physical deterioration prior to the cardiac arrest. 2. For persons who have severe dementia, and possibly for those with moderate dementia (CPR is intended to prevent premature death and is not appropriate in a person who has advanced and debilitating symptoms of aging.) 3. For patients with cancer (who rarely survive CPR according to the medical literature.) However, some patients have minimal cancer and deserve CPR. 4. For victims of the AIDS epidemic for whom cardiac arrest is a late complication. Exciting advances in treatment recently reported seem most likely to delay the occurrence of cardiac arrest but not alter subsequent outcome.

It is intended that indications will be revised as new knowledge emerges. In any scenario we expect that providers will need to make individual judgments.

\section{Acknowledgements}

The Colorado Trust partially supported this project through its funding of the Colorado Collective For Medical Decisions, an open organization of medical care professionals and citizens concerned with inappropriate or ineffective medical care. Members of the Adult Intensive Care Subcommittee shared their invaluable expertise, experience and insight with us, and helped formulate the recommendation. Our thanks to those who commented on the manuscript: Father Bill Pounds, Susan Fox Buchanan, Barbara Lundy, Ranaan Gillon and the fournal of Medical Ethics reviewers. The analysis in this paper is the responsibility of the authors.

Mark Hilberman, MD, is Director of the Carbondale Clinic in Carbondale, Colorado. Fean Kutner, MD, MSPH, is Assistant Professor of Medicine in the University of Colorado Health Sciences Center, Denver, Colorado. Debra Parsons, MD, FACP, is Director of Clinical Inpatient Services, Internal Medicine Residency Program at St foseph Hospital, Denver, Colorado and Donald $\mathcal{f}$ Murphy MD, FACP, is a Geriatrician and Director of the Colorado Collective for Medical Decisions.

\section{References}

1 Emergency Cardiac Care Committee and Subcommittees AHA. Guidelines for emergency cardiac care, I-IX. Fournal of the American Medical Association 1992; 268: 2172-295.

2 Rothman DJ. Strangers at the bedside. New York: Basic Books, 1991.

3 Zussman R. Intensive care, medical ethics and the medical profession. Chicago: University of Chicago Press, 1992.
4 Emergency Cardiac Care Committee and Sub-T committees AHA. Guidelines for emergency cardiac care, VIII: ethical considerations in resuscitation. Fourna f? of the American Medical Association 1992; 268: 2282-8.

5 Cohn EB, Lefevre F, Yarnold PR, Arron MJ, Martinঙ GJ. Predicting survival from in-hospital CPR: meta-음 analysis and validation of prediction model. Fournal ofo General Internal Medicine 1993; 8: 347-53.

6 Ebell MH. Prearrest predictors of survival following in $-\vec{\nabla}$ hospital cardiopulmonary resuscitation: a metaanalysis. Fournal of Family Practice 1992; 34: 551-8. के

7 Nuland SB. How we die. New York: Knopf, $1993 . \quad \overrightarrow{0}$

8 Golub ES. The limits of medicine. New York: TimesBooks/Random House, 1994.

9 Alexandrov AV, Pullicino PM, Meslin EM, et al $\stackrel{\text { S }}{S}$ Agreement on disease-specific criteria for do-not-resuscitate orders in acute stroke. Stroke 1996; 27: 232-7.

10 Quality Standards Subcommittee of the AmericancW Academy of Neurology. Practice parameters: assess-os ment and management of patients in the persistento vegetative state (summary statement). Neurology $1995 ; \overrightarrow{0}$ 45: $1015-18$.

11 Beauchamp TL, Childress JF. Principles of biomedical ethics [4th ed]. New York: Oxford University Press, 1994.

12 Bower AG, Bennett VR, Dillon JB. Investigation of the care and treatment of poliomyelitis patients. Annals of Western Medicine and Surgery 1950; 4: 561-82, 687-716. -

13 Lassen HCA. Preliminary report on the 1962 epidemic $\overrightarrow{0}$ of poliomyelitis in Copenhagen. Lancet 1953; 1: 37. 응 가

14 Kouwenhoven WB, Jude JR, Knickerbocker GS. Closed-chest cardiac massage. Fournal of the Ameris Medical Association 1960; 173: 1064-7.

15 Dans PE, Nevin KL, Seidman CE, MacArthur JC, Kariya ST. Inhospital CPR 25 years later: why haso survival decreased? Southern Medical fournal 1985; 78:尺ْ 1174-8.

16 Theimann DR, Bass EB, Powe NR, Halperin HR, Steinberg EP. Pre-arrest comorbidity, outcome and cost in inpatient CPR (abstract). Circulation 1994; 90, 4, 2: supp 2: I-288.

17 Brymer C, Gangbar E, O'Rourke K, Naglie G. Age as a亏 determinant of cardiopulmonary resuscitation outcome in the coronary care unit. Fournal of the American Geriatrics Society 1995; 43: 634-7.

18 Ballew KA, Philbrick JT, Caben DE, Schorling JB.ᄋ Predictors of survival following in-hospital cardio- 2 pulmonary resuscitation: a moving target. Archives of음 Internal Medicine 1994; 154: 2426-32.

19 Herlitz J, Ekstrom L, Wennerblom B, Axelsson A, 음 Bang A, Holmberg S. Prognosis among survivors of prehospital cardiac arrest. Annals of Emergency Medicines 1995; 25: 58-63.

20 Vitelli CE, Cooper K, Rogatko A, Brennan MF. N Cardiopulmonary resuscitation and the patient with cancer. Fournal of Clinical Oncology 1991; 9: 111-15:0

21 Dull SM, Graves JR, Larsen MP, Cummins RỌ Expected death and unwanted resuscitation in the pre- $\bar{\Phi}$ hospital setting. Annals of Emergency Medicine 1994; $23: \stackrel{\text { ? }}{+}$ 997-1002.

22 Lombardi G, Gallagher EJ, Gennis P. Outcome of out-O우 of-hospital cardiac arrest in New York City. Fournal of $\overrightarrow{\mathbb{Q}}$ the American Medical Association 1994; 271: 678-83.

23 Becker LB, Han BH, Meyer PM, Wright FA, Rhodes $\mathrm{KV}$, Smith DW, et al. Racial differences in the incidence of cardiac arrest and subsequent survival. New England fournal of Medicine 1993; 329: 600-6. 
24 Bedell SE, Delbanco TL, Cook EF, Epstein FH. Survival after cardiopulmonary resuscitation in the hospital. New England Fournal of Medicine 1983; 309: 569-76.

25 Herlitz J, Ekstrom L, Wennerblom B, Axelsson A, Bang A, Holmberg S. Effect of bystander initiated cardiopulmonary resuscitation on ventricular fibrillation and survival after witnessed cardiac arrest outside hospital. British Heart fournal 1994; 72: 408-12.

26 Berek K, Lechleitner P, Luef G, et al. Early determination of neurological outcome after prehospital cardiopulmonary resuscitation. Stroke 1995; 26: 543-9.

27 Ronco R, King W, Donley DK, Tilden SJ. Outcome and cost at a children's hospital following resuscitation for out-of-hospital cardiopulmonary arrest. Archives of Pediatric Adolescent Medicine 1995; 149: 210-14.

28 Rogove HJ, Safar P, Sutton-Tyrrell KS, et al. Old age does not negate good cerebral outcome after cardiopulmonary resuscitation: analyses from the brain resuscitation clinical trials. Critical Care Medicine 1995; 23: 18-25.

29 Solomon NA, Glick HA, Russo CJ, Lee J, Schulman KA. Patient preferences for stroke outcomes. Stroke 1994; 25: 1721-5.

30 Herhold S. Fruitless rescues: paramedics rush dead people to hospitals, costing millions. Mercury News 1993 Aug 15: 1A,ff.

31 Tresch D, Heudebert G, Kutty K, Ohlert J, VanBeek K, Masi A. Cardiopulmonary resuscitation in elderly patients hospitalized in the 1990s: a favorable outcome. Fournal of the American Geriatrics Society 1994; 42: 137-41.

32 Gordon M, Cheung M. Poor outcome of on-site CPR in a multi-level geriatric facility: three and a half years experience at the Baycrest Centre for Geriatric Care. Fournal of the American Geriatrics Society 1993; 41: 163-6.

33 Applebaum GE, King JE, Finucane TE. The outcomes of CPR inititated in nursing homes. Fournal of the American Geriatrics Society 1990; 38: 197-200.

34 Bialecki L, Woodward RS. Predicting death after CPR: experience at a non-teaching community hospital with a full-time critical care staff. Chest 1995; 108: 1009-17.

35 Kentsch $M$, Stendel $M$, Berkel H, Bueller-Esch G. Early prediction of prognosis in out-of-hospital cardiac arrest. Intensive Care Medicine 1990; 16: 378-83.

36 Martens PR, Mullie A, Buylaert W, Calle P, van Hoeyweghen R, and the Belgian Cerebral Resuscitation Group. Early prediction of non-survival for patients suffering cardiac arrest - a word of caution. Intensive Care Medicine 1992; 18: 11-14.

37 Gove PB and the Merriam-Webster editorial staff. Webster's third new international dictionary. Springfield, MA: G and C Merriam Co, 1976.

38 Tomlinson T, Brody H. Futility and the ethics of resuscitation. Fournal of the American Medical Association 1990; 264: 1276-80.

39 Schneiderman LJ, Jecker NS. Wrong medicine: doctors, patients and futile treatment. Baltimore: The Johns Hopkins University Press, 1995.

40 Howard PK. The death of common sense: how law is suffocating America. New York: Random House, 1994.

41 McCormick RA. To save or let die. Foumal of the American Medical Association 1974; 229: 172-6.

42 Rawls J. A theory of justice. Cambridge, MA: The Belknap Press of Harvard University Press, 1971.

43 Mill JS. Utilitarianism. On liberty and utilitarianism. New York: Bantam Books, 1993.
44 Engelhardt Jr HT. The foundations of bioethics [2d ed]. New York: Oxford, 1996.

45 Morgan R, King D, Prajapati C, Rowe J. Views of elderly patients and their relatives on cardiopulmonary resuscitation. British Medical fournal 1994; 308: 1677-8.

46 Meystre CJN, Ahmedzai S, Burley NMJ. Terminally ill patients may want to live. British Medical fournal 1994; 309: 409.

47 Peet J. Survey of health care. The Economist 1991 July 6.

48 Simpson WF. Comparative longevity in a college cohort of Christian Scientists. Foumal of the American Medical Association 1989; 262: 1657-8.

49 Drucker PF. A century of social transformation. Managing in a time of great change. New York: Truman Talley Books/Dutton, 1995: ch 21.

50 McGinnis JM, Foege WH. Actual causes of death in the United States. Fournal of the American Medical Association 1993; 270: 2207-12.

51 Hurowitz JC. Toward a social policy for health. New England Fournal of Medicine 1993; 329: 130-3.

52 Kiple KF, ed. The Cambridge world history of human disease. Cambridge: Cambridge University Press, 1993.

53 Bergthold LA. Medical necessity: do we need it? Health Affairs 1995; 14: 180-90.

54 Reiser SJ. Criteria for standard versus experimental therapy. Health Affairs 1994; 13: 127-36.

55 Mandelblatt JS, Fahs MC. The cost-effectiveness of cervical cancer screening for low-income elderly women. Fournal of the American Medical Association 1988; 259: 2409-13.

56 Horstkotte D. Quality of life after heart valve replacement. In: Walter PJ, ed. Quality of life after open heart surgery. Dordrecht: Kluwer, 1992:101-4.

57 Weinstein M, Stason W. Cost-effectiveness of interventions to prevent or treat coronary heart disease. Annual Review of Public Health 1985; 6: 41-3.

58 Edelson JT, Weinstein MC, Tosteson ANA, et al. Longterm cost-effectiveness of various initial monotherapies for mild to moderate hypertension. Foumal of the American Medical Association 1990; 263: 408-13.

59 Califf RM, Harrell FE, Lee KL, et al. The evolution of medical and surgical therapy for coronary artery disease, a 15-year perspective. Foumal of the American Medical Association 1989; 261: 2077-86.

60 Levinsky NG. The organization of medical care: lessons from the Medicare End Stage Renal Disease Program. New England foumal of Medicine 1993; 329: 1395-9.

61 Kinosian BP, Eisenberg JM. Cutting into cholesterol. Foumal of the American Medical Association 1988; 259: 2249-54.

62 Wachter RM, Luce JM, Safrin S, et al. Costs and outcome of intensive care for patients with AIDS, pneumocystis carinii pneumonia, and severe respiratory failure. Foumal of the American Medical Association 1995; 273: 230-5.

63 Schapira DV, Studnicki J, Bradham DD, et al. Intensive care, survival and expense of treating critically ill cancer patients. Foumal of the American Medical Association 1993; 269: 783-6.

64 Fineberg HV, Scadden D, Goldman L. Care of patients with a low probability of acute myocardial infarction. New England fournal of Medicine 1984; 310: 1301-7.

65 Murphy DJ, Matchar DB. Life-sustaining therapy: a model for appropriate use. Foumal of the American Medical Association 1990; 264: 2103-8. 